\title{
Time course of vascular response after an a priori strategy of bare metal stent implantation post-dilated with a paclitaxel-coated balloon: Implementation of a three-dimensional analysis algorithm with optical coherence tomography
}

Sylvia Otto ${ }^{1}$, Johannes Gassdorf ${ }^{1}$, Kristina Nitsche ${ }^{1}$, Juan Luis Gutiérrez-Chico ${ }^{2}$, Aleh Kryvanos $^{3}$, Björn Goebel ${ }^{1}$, Hans R. Figulla ${ }^{1}$, Tudor C. Poerner ${ }^{1}$

${ }^{1} 1^{\text {st }}$ Clinic of Medicine, Division of Cardiology, University Hospital of Jena, Germany ${ }^{2}$ Department of Interventional Cardiology, Klinikum Frankfurt/Oder, Germany

${ }^{3}$ UltraOsteon, Mannheim, Germany

\begin{abstract}
Background: An a priori combined therapy of a bare metal stent post-dilated with a paclitaxel-coated balloon (PCB) was investigated with optical coherence tomography (OCT) at 2 and 6 months regarding vessel response. Previous studies have shown inconsistent results and the time course of vessel healing after such an interventional strategy is unknown.

Methods: Thirty-three de novo lesions in 32 patients were electively treated. Six-month OCT analysis was available in 24 lesions. Two-month OCT follow-up was obtained in 16 lesions. Sequential OCT at 2 and 6 months was available in 7 patients. A novel 3-dimensional picture of vessel segments as spread outs was implemented.

Results: Severe incomplete stent apposition (ISA) accompanied by significantly lower strut coverage were found at 2-month compared with 6-month follow-up (ISA struts: $11.4 \pm 11.8 \%$ vs. $1.8 \pm 4.8 \%, p=0.001$; uncovered struts: $14.5 \pm 14.8 \%$ vs. $2.0 \pm 5.3 \%, p=0.001)$. ISA size diminished over time and the possibly observed phenomenon of positive vessel remodeling (remodeling volume: $4.9 \pm 5.9 \mathrm{~mm}^{3}$ at 2 -months $v$ s. $2.0 \pm 2.6 \mathrm{~mm}^{3}$ at 6 -months; $p=0.042$ ) was largely reversible in most lesions.

Conclusions: Bare metal stenting with adjunctive application of paclitaxel by a coated balloon shows transient severe incomplete strut apposition, most likely due to focal positive vessel remodeling. Thus, caution is needed in bailout situations following a PCB angioplasty. A novel illustration of OCT parameters as "carpet views" enables a comprehensive analysis of investigated stents. (Cardiol J 2016; 23, 3: 296-306)

Key words: coronary artery disease, optical coherence tomography, drug-coated balloon, percutaneous coronary intervention
\end{abstract}

Address for correspondence: Dr Sylvia Otto, Klinik für Innere Medizin I, Universitätsklinikum Jena, Erlanger Allee 101, 07747 Jena, Germany, tel: +49 364193245 47, fax: +49364193241 02, e-mail: sylvia.otto@med.uni-jena.de 


\section{Introduction}

Drug-coated balloons (DCB) haven proven efficacy in the treatment of in-stent restenosis or angioplasty of de novo lesions in small vessels [1,2]. Most DCBs are coated with the mitotic inhibitor - paclitaxel. The SeQuent Please ${ }^{\mathrm{TM}} \mathrm{DCB}$ releases $>90 \%$ of its paclitaxel load by single inflation of $\geq 30 \mathrm{~s}[2,3]$. An a priori combination therapy of bare metal stent (BMS) implantation post-dilated with a paclitaxel-coated balloon (PCB) seems worth investigating, since it combines the mechanical forces of a stent with an antiproliferative drug applied in a "single-shot" fashion over a large contact surface to the vessel wall [4].

Previous studies have shown inconsistent results regarding the antiproliferative strength of such an adjunctive procedure [5-10]. Yet, no data about the time course of arterial vessel response and stent coverage after such a procedure is available. Optical coherence tomography (OCT) allows precise vessel and stent evaluation in vivo. However, a three-dimensional (3D) illustration of investigated vessel segments that enables simple recognition of analyzed OCT parameters at a glance is needed.

We aimed to evaluate vessel response at 2 and 6 months after an $a$ priori therapy with a BMS post-dilated with a $\mathrm{PCB}$ regarding incomplete stent apposition (ISA) and coverage using OCT. A novel 3D analysis of stented vessel segments and its comprehensive illustration as spread out charts (“carpet-views") was implemented.

\section{Methods}

\section{Study design}

Briefly, patients with stable coronary artery disease and indication for elective percutaneous coronary intervention (PCI) of a native coronary lesion were included into the OCTOPUS trial. Patients were randomly assigned to receive treatment either with the Xience $\mathrm{V}^{\mathrm{TM}}$ (Abbott Vascular, Illinois, USA) drug-eluting stent (DES) or a combination of the BMS Coroflex Blue ${ }^{\mathrm{TM}}$ post-dilated with the PCB SeQuent Please ${ }^{\mathrm{TM}}$ (both BBraun Melsungen, Germany) [9, 11]. This sub-study of the aforementioned trial focuses only at the treatment arm BMS + PCB at 2- and 6-month OCT follow-up (Fig. 1). Due to ethical reasons, only patients with an indication for staged PCI received serial OCT investigation at both follow-up intervals. The study was conducted at the University Hospital of Jena according to the ethical principles of the Declaration of Helsinki.

\section{Study devices and interventions}

The detailed procedural protocol has been published. Only $2.5 \mathrm{~mm}$ or $3.0 \mathrm{~mm}$ stent diameters with two stent lengths ( $16 \mathrm{~mm}$ and $25 \mathrm{~mm}$ ) were allowed. Lesion preparation with pre-dilation or direct stenting was conducted on the operator's discretion. To provide a safety margin at the stent edges, all BMS were post-dilated with a longer PCB $(20 \mathrm{~mm}$ or $30 \mathrm{~mm})$. Afterwards no further intervention of the study lesion was undertaken.

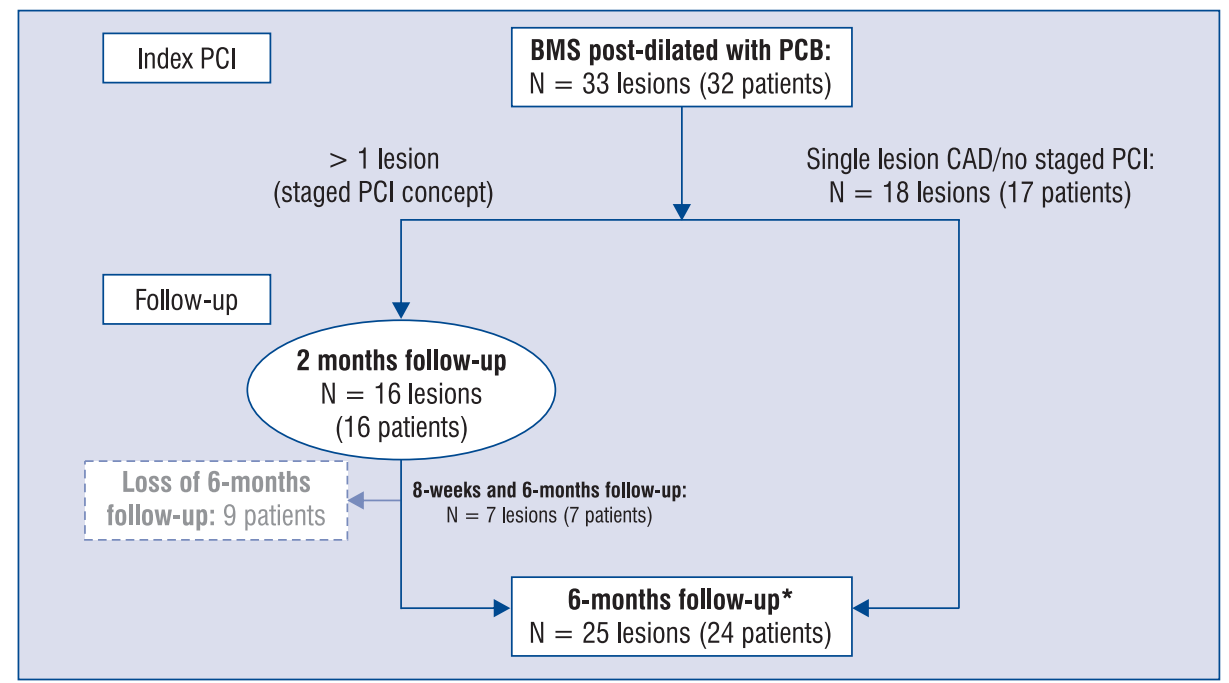

Figure 1. Patient flowchart; BMS — bare metal stent; CAD — coronary artery disease; PCB — paclitaxel-coated balloon; $\mathrm{PCl}$ - percutaneous coronary intervention; *1 patient received only quantitative coronary angiography at follow-up. 
Table 1. Baseline clinical characteristics of the study population, patient-based analysis.

\begin{tabular}{|c|c|c|c|c|}
\hline Characteristics & $\begin{array}{l}\text { Patients with 2-month } \\
\text { follow-up }\end{array}$ & $\begin{array}{l}\text { Patients with 6-month } \\
\text { follow-up }\end{array}$ & $\mathbf{P}$ & All \\
\hline $\mathrm{N}$ & $16^{\#}$ & $24^{\#}$ & & 32 \\
\hline Age & $69.1 \pm 7.2$ & $68.9 \pm 7.8$ & 0.953 & $69.3 \pm 7.7$ \\
\hline Male gender & $11(68.8 \%)$ & $15(62.5 \%)$ & 0.685 & $22(68.8 \%)$ \\
\hline \multicolumn{5}{|l|}{ Coronary risk factors: } \\
\hline Hypertension & $16(100 \%)$ & $24(100 \%)$ & 0.999 & $32(100 \%)$ \\
\hline Diabetes mellitus & $10(62.5 \%)$ & $7(29.2 \%)$ & 0.037 & $14(43.8 \%)$ \\
\hline Hyperlipidemia & $11(68.8 \%)$ & $19(79.2 \%)$ & 0.320 & $24(75.0 \%)$ \\
\hline Smoker/Ex-smoker & $3(18.8 \%)$ & $9(37.5 \%)$ & 0.722 & $9(28.1 \%)$ \\
\hline Glomerular filtration rate $[\mathrm{mL} / \mathrm{min}]$ & $70.7 \pm 25.2$ & $64.3 \pm 22.8$ & 0.418 & $69.2 \pm 22.4$ \\
\hline Low-density lipoprotein [mmol/L] & $2.3 \pm 0.9$ & $3.0 \pm 1.6$ & 0.148 & $2.8 \pm 1.5$ \\
\hline Previous myocardial infarction & $6(37.5 \%)$ & $4(16.7 \%)$ & 0.136 & $8(25.0 \%)$ \\
\hline Previous coronary artery bypass graft & 0 & 0 & 0.999 & 0 \\
\hline
\end{tabular}

Data are expressed as mean \pm standard deviation or number (\%) of subjects; ${ }^{7} 7$ patients with 8-week and 6-month follow-up belong to both groups

\section{Angiographic analysis}

Quantitative coronary angiography (QCA) was performed according to the 15-coronary tree segment system (CAAS version 5.9.2, 2012, Pie Medical Imaging, Maastricht, Netherlands) by two observers (K.N. and S.O.). Late lumen loss was defined as 'final minimal lumen diameter (MLD) post-procedure - MLD at follow-up', and net luminal gain as 'MLD at follow-up — baseline MLD'. Procedural success was defined as a residual stenosis $<20 \%$ during the final angiography without any flow limiting dissections. Angiographic diameter restenosis of $\geq 50 \%$ was defined as significant [12].

\section{Optical coherence tomography}

Time-domain OCT imaging (M2 CV system, LightLab Imaging Inc., Westford, MA, USA) of the study stent was performed and images were analyzed in $1 \mathrm{~mm}$ steps. The detailed OCT protocol has been published $[9,11]$.

\section{OCT parameters}

Struts were counted per cross-section and classified as either covered or uncovered, and regarding apposition as mal-apposed or apposed/ /embedded or laying over a side branch ostium. ISA was defined as a mal-apposed stent strut $>70 \mu \mathrm{m}$ from the adluminal strut side to the luminal vessel wall. Among others, the following parameters were calculated: (1) proliferation volume $/ \mathrm{cm}$ stent length; (2) peak and median relative proliferation area $=(1-[$ minimal lumen area/stent area within the same frame] $\times 100$; (3) remodeling volume
$=$ integral of (lumen area - stent area + ISA area) over stent length; (4) total and relative ISA volumes, and (5) total and relative ISA surface areas. Volumetric parameters were computed through the integral of area measurements over stent length.

\section{Statistical analysis}

Statistical analysis was performed using SPSS for Windows (version 21.0.0.0, SPSS, Chicago, Ill). Continuous variables are expressed as mean \pm standard deviation and were tested with the oneway analysis of variance in case of normal distributed variables. Categorical variables are presented as percentages and analyzed with the Pearson $\chi^{2}$ test. Repeated measurements of patients with both, 2- and 6-month follow-up, were analyzed with the non-parametric paired Wilcoxon signedrank test. Statistical significance was assumed for p-values $<0.05$.

\section{Results}

\section{Study population}

Altogether 33 lesions were treated. Six-month follow-up with QCA and OCT analyses was available in 24 patients. Sixteen patients returning to the clinic for staged PCI within 2 months after index PCI received OCT imaging of the study vessel. Among them, 7 patients also returned for 6-month invasive follow-up (Fig. 1). Tables 1 and 2 show clinical and procedural characteristics. Predilation was conducted with a mean of $1.69 \pm 2.2$ in the 2 -month follow-up group and $0.96 \pm 1.3$ times 
Table 2. Procedural and lesion characteristics, lesion-based analysis.

\begin{tabular}{|c|c|c|c|c|}
\hline Characteristics & $\begin{array}{l}\text { Patients with 2-month } \\
\text { follow-up }\end{array}$ & $\begin{array}{l}\text { Patients with 6-month } \\
\text { follow-up }\end{array}$ & $\mathbf{P}$ & All \\
\hline $\mathrm{N}$ & $16^{\#}$ & $25^{* \#}$ & & $33^{* \#}$ \\
\hline Follow-up interval [days] & $61.9 \pm 11.3$ & $189.2 \pm 20.8$ & $<0.001$ & \\
\hline Baseline stenosis [\%] & $82.8 \pm 10.9$ & $72.5 \pm 15.3$ & 0.024 & $74.1 \pm 14.4$ \\
\hline Target vessel: & & & 0.932 & \\
\hline Right coronary artery & $4(25.0 \%)$ & $7(28.0 \%)$ & & $9(27.3 \%)$ \\
\hline Left circumflex & $4(25.0 \%)$ & $7(28.0 \%)$ & & $8(24.2 \%)$ \\
\hline Left anterior descending & $8(50.0 \%)$ & $11(44.0 \%)$ & & $16(48.5 \%)$ \\
\hline Lesion type (ACC/AHA): & & & 0.961 & \\
\hline Type A & 0 & 0 & & 0 \\
\hline Type B & $10(62.5 \%)$ & $17(68.0 \%)$ & & $22(66.7 \%)$ \\
\hline Type C & $6(37.5 \%)$ & $8(32.0 \%)$ & & $11(33.3 \%)$ \\
\hline \multicolumn{5}{|l|}{ Procedural parameters: } \\
\hline $2.5 \mathrm{~mm}$ stent diameter & $5(31.3 \%)$ & $7(28.0 \%)$ & \multirow{2}{*}{0.832} & $10(30.3 \%)$ \\
\hline $3.0 \mathrm{~mm}$ stent diameter & $11(68.8 \%)$ & $18(72.0 \%)$ & & $23(69.7 \%)$ \\
\hline Stent length [mm] & $20.5 \pm 4.6$ & $19.7 \pm 4.5$ & 0.575 & $19.9 \pm 4.5$ \\
\hline Overstretch ratio [\%] & $103.2 \pm 10.4$ & $109.3 \pm 21.2$ & 0.304 & $106.9 \pm 17.8$ \\
\hline Direct stenting & $5(31.3 \%)$ & $14(56.0 \%)$ & 0.379 & $15(45.5 \%)$ \\
\hline Ostial lesion & 0 & $1(4.0 \%)$ & 0.418 & $1(3.0 \%)$ \\
\hline Additional stenting & $2(12.5 \%)$ & $5(20.0 \%)$ & 1.0 & $5(15.2 \%)$ \\
\hline Chronic total occlusion & $2(12.5 \%)$ & $3(12.0 \%)$ & 0.962 & $4(12.1)$ \\
\hline Bifurcation lesion & $2(12.5 \%)$ & $4(16.0 \%)$ & 0.757 & $5(15.2)$ \\
\hline Side branch dilation & 0 & $1(4.0 \%)$ & 0.418 & $1(3.0 \%)$ \\
\hline Time of fluoroscopy [min] & $11.9 \pm 7.2$ & $10.2 \pm 9.5$ & 0.573 & $10.8 \pm 9.4$ \\
\hline Procedural success & $16(100 \%)$ & $25(100 \%)$ & 0.999 & $33(100 \%)$ \\
\hline
\end{tabular}

*1 patient had only an angiographic follow-up without optical coherence tomography imaging; ${ }^{*} 7$ lesions (7 patients) were included in both groups due to sequential follow-up and 1 patient was included with 2 study lesions

in the 6-month follow-up group (NS). The relation of inflated stent diameters (SD) to reference vessel diameters (RVD: given as mean values of two diameter measurements per proximal and distal reference site) yields an overstretch ratio $(\mathrm{SD} /$ $/ \mathrm{RVD}_{\mathrm{OCT}}$ ) of $106.9 \pm 17.8 \%$ (Table 2 ).

\section{Comparison of invasive follow-up at 2 and 6 months}

Strut level analysis showed significantly more ISA at 2 months compared to 6 month-follow-up $(11.4 \pm 11.8 \%$ vs. $2.2 \pm 5.0 \%$; $\mathrm{p}=0.001)$ (Table 3 , Fig. 2), which was depicted with various OCT parameters (number of ISA regions, ISA volumes, ISA depth and ISA surface areas) (Table 3) and went along with significantly more uncovered struts compared to 6 -month follow-up $(14.5 \pm 14.8 \%$ vs. $2.0 \pm 5.3 \%, p=0.001)$ (Table 3 ). We noted positive vessel remodeling with larger remodeling volumes after 2 months compared to 6 months $\left(0.26 \pm 0.35 \mathrm{~mm}^{3} / \mathrm{cm}\right.$ vs. $\left.0.11 \pm 0.14 \mathrm{~mm}^{3} / \mathrm{cm}, \mathrm{p}=0.071\right)$. At 6 months the suspected positive vessel remodeling with severe ISA was largely reversible (Table 3, Fig. 2). Not all parameters reached statistical significance in this small sample size. OCT analysis revealed well expanded stents (inflated $\mathrm{SD}_{\text {nominal }}: 2.86 \pm$ \pm 0.23 vs. median measured $\mathrm{SD}_{\mathrm{OCT}}: 2.89 \pm 0.41$ ). Measured SD and stent areas (SA) in relation to their inflated nominal values ( $\left[\mathrm{SD}_{\text {median }}-\mathrm{SD}_{\text {nominal }}\right] /$ $/ \mathrm{SD}_{\text {nominal }}$; $\left.\left[\mathrm{SA}_{\text {median }}-\mathrm{SA}_{\text {nominal }}\right] / \mathrm{SA}_{\text {nominal }}\right)$ indicated slight overexpansion of most stents $(0.8 \pm 10.9 \%$; and $3.3 \pm 20.6 \%$, respectively). We found no relationship between stent sizes and ISA.

\section{Serial analysis of the same stent at 2- and 6-month follow-up}

We found significantly greater remodeling volumes, larger ISA depths, more ISA regions and more uncovered struts at the early 2 -month 
Table 3. Comparison of implanted stents at 8-week and 6-month invasive follow-up, lesion-based analysis.

\begin{tabular}{|c|c|c|c|}
\hline Characteristics & $\begin{array}{l}\text { 2-months follow-up } \\
\qquad(\mathrm{n}=16)^{\#}\end{array}$ & $\begin{array}{l}\text { 6-months follow-up } \\
(\mathrm{n}=25)^{* \#}\end{array}$ & $\mathbf{P}$ \\
\hline \multicolumn{4}{|l|}{ QCA parameters } \\
\hline $\mathrm{RLD}[\mathrm{mm}]$ & $2.61 \pm 0.3$ & $2.65 \pm 0.31$ & 0.714 \\
\hline MLD at baseline [mm] & $0.43 \pm 0.28$ & $0.72 \pm 0.43$ & 0.027 \\
\hline MLD at fallow-up [mm] & $2.23 \pm 0.45$ & $2.06 \pm 0.41$ & 0.219 \\
\hline Post-procedure MLD [mm] & $2.31 \pm 0.4$ & $2.29 \pm 0.34$ & 0.794 \\
\hline Baseline stenosis [\%] & $82.8 \pm 10.9$ & $72.5 \pm 15.3$ & 0.024 \\
\hline Post-procedure stenosis [\%] & $10.8 \pm 10.2$ & $12.7 \pm 9.6$ & 0.536 \\
\hline Stenosis at follow-up [\%] & $14.4 \pm 12.5$ & $21.8 \pm 13.0$ & 0.080 \\
\hline Late lumen loss at follow-up & $0.09 \pm 0.14$ & $0.23 \pm 0.21$ & 0.028 \\
\hline Net luminal gain at follow-up & $1.82 \pm 0.5$ & $1.38 \pm 0.6$ & 0.024 \\
\hline \multicolumn{4}{|l|}{ OCT - proliferation analysis } \\
\hline Analyzed stent length [\%] & $98.4 \pm 11.1$ & $71.7 \pm 24.8$ & $<0.001$ \\
\hline Relative proliferation volume $\left[\mathrm{mm}^{3} / \mathrm{cm}\right.$ stent] & $5.1 \pm 7.8$ & $13.6 \pm 7.4$ & 0.001 \\
\hline Peak relative proliferation area [\%] & $26.1 \pm 13.6$ & $40.0 \pm 15.0$ & 0.009 \\
\hline Median relative proliferation area [\%] & $10.2 \pm 8.0$ & $23.1 \pm 10.5$ & $<0.001$ \\
\hline \multicolumn{4}{|l|}{ OCT - ISA analysis } \\
\hline Positive remodeling volume $\left[\mathrm{mm}^{3}\right]$ & $4.9 \pm 5.9$ & $2.0 \pm 2.6$ & 0.042 \\
\hline Positive remodeling volume $\left[\mathrm{mm}^{3} / \mathrm{cm}\right.$ stent $]$ & $0.26 \pm 0.35$ & $0.11 \pm 0.14$ & 0.071 \\
\hline Number of ISA regions & $2.1 \pm 2.2$ & $0.3 \pm 0.6$ & $<0.001$ \\
\hline Maximal ISA depth $[\mu \mathrm{m}]$ & $215 \pm 690$ & $10 \pm 25$ & 0.151 \\
\hline Maximal ISA volume $\left[\mathrm{mm}^{3}\right]$ & $3.62 \pm 7.7$ & $0.41 \pm 1.6$ & 0.054 \\
\hline Total ISA volume $\left[\mathrm{mm}^{3}\right]$ & $5.62 \pm 12.6$ & $0.46 \pm 1.8$ & 0.054 \\
\hline Relative ISA volume [\%] & $3.67 \pm 8.0$ & $0.37 \pm 1.5$ & 0.056 \\
\hline Total ISA surface $\left[\mathrm{mm}^{2}\right]$ & $5.27 \pm 6.7$ & $1.36 \pm 4.4$ & 0.032 \\
\hline Relative ISA surface [\%] & $2.79 \pm 3.6$ & $0.83 \pm 2.8$ & 0.063 \\
\hline Struts with ISA [\%] & $11.4 \pm 11.8$ & $1.8 \pm 4.8$ & 0.001 \\
\hline Uncovered struts [\%] & $14.5 \pm 14.8$ & $2.0 \pm 5.3$ & 0.001 \\
\hline
\end{tabular}

*1 patient had only an angiographic follow-up without OCT imaging; ${ }^{\# 7}$ lesions (7 patients) were included in both groups due to sequential follow-up and 1 patient was included with 2 study lesions; ISA — incomplete stent apposition; MLD — minimal lumen diameter; OCT — optical coherence tomography; QCA — quantitative coronary angiography; RLD — reference lumen diameter

follow-up and reversible effects after 6 months (Table 4) corresponding to the shown interindividual analysis above (Figs. 3, 4).

\section{OCT “carpet view”}

Of each investigated stented vessel segment, a 3D spread out chart was created. The 3D illustrates (1) stent circumference (X-axis and blue line), (2) analyzed stent or vessel length and, (3) degree of stent incorporation in the vessel wall (neointimal thickness of stent struts, negative values), or distance of struts with ISA from luminal border (positive values) (Figs. 3, 4). Stent struts are displayed as colored dots depending on their quality of coverage and apposition.

\section{Discussion}

Data regarding an a priori strategy of BMS $+\mathrm{PCB}$ in de novo coronary artery stenoses are still limited [5-9]. Previously, the final 5-year results of the PERfECT trial, a randomized study of BMS/ /PCB vs. BMS in de novo stenoses showed superiority for an adjunctive delivery of paclitaxel by a coated balloon for clinical endpoints [10]. O the contrary, another recently published randomized study found an increased stent thrombosis rate for the concept of BMS + PCB compared to the paclitaxel-eluting stents [13]. This is the first study investigating the course of vessel healing after a BMS + PCB approach using QCA and OCT. 


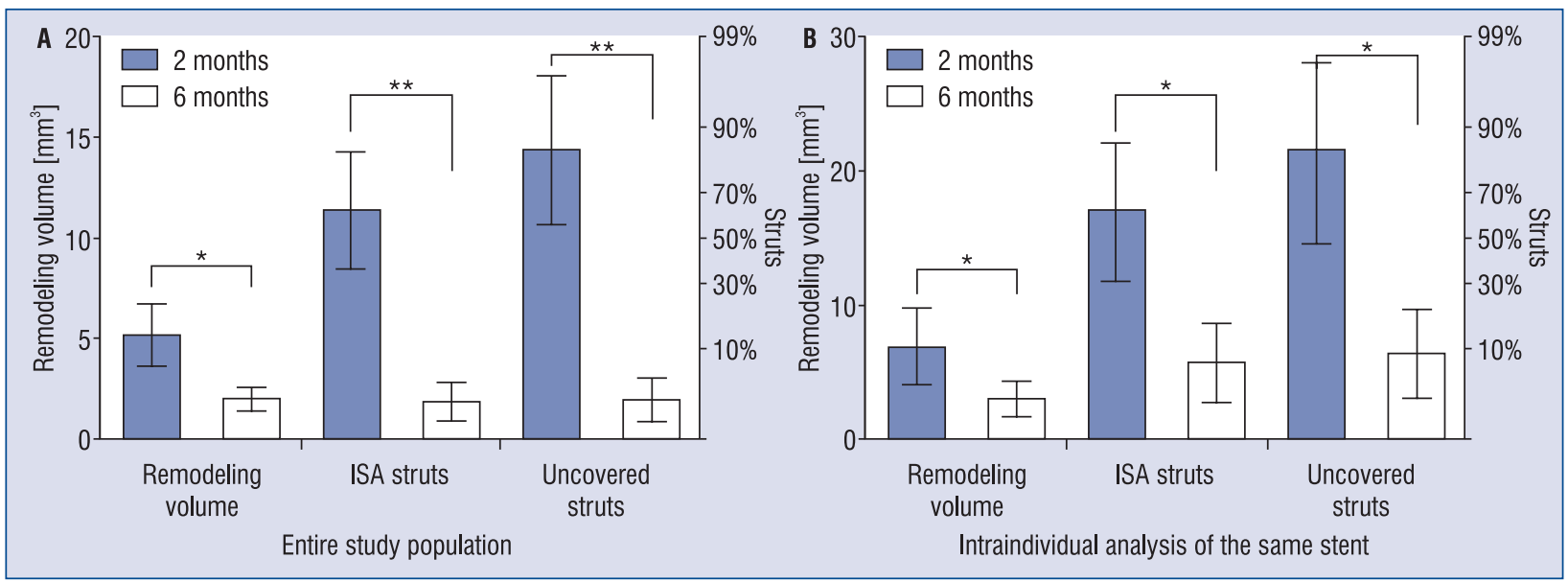

Figure 2. Remodeling volume, percent struts with incomplete stent apposition (ISA) and percent uncovered struts (means and standard errors of the mean) comparing study stents after 2 and 6 months. A. Entire study population; B. Serial comparison in 7 patients; ${ }^{*} p<0.05 ;{ }^{* *} p=0.001$.

Table 4. Serial analysis of the same study stent at 2- and 6-month follow-up, lesion-based analysis [mean \pm SD (median)].

\begin{tabular}{|c|c|c|c|}
\hline & $\begin{array}{l}\text { 2-month follow-up } \\
(\mathbf{n}=7)\end{array}$ & $\begin{array}{l}\text { 6-month follow-up } \\
\qquad(\mathrm{n}=7)\end{array}$ & $\mathbf{P}$ \\
\hline Follow-up interval [days] & $67.7 \pm 8.0(65.0)$ & $204.9 \pm 22.4(209.0)$ & 0.018 \\
\hline \multicolumn{4}{|l|}{ QCA parameters } \\
\hline $\mathrm{RLD}[\mathrm{mm}]$ & \multicolumn{2}{|c|}{$2.6 \pm 0.37(2.6)$} & \\
\hline MLD at baseline $[\mathrm{mm}]$ & \multicolumn{2}{|c|}{$0.36 \pm 0.3(0.3)$} & \\
\hline MLD at follow-up [mm] & $2.26 \pm 0.48(2.32)$ & $2.15 \pm 0.47(2.2)$ & 0.018 \\
\hline Baseline stenosis [\%] & \multicolumn{2}{|c|}{$85.6 \pm 11.5(84.0)$} & \\
\hline Stenosis at follow-up [\%] & $12.3 \pm 13.6(8.0)$ & $16.6 \pm 14.2(12.0)$ & 0.018 \\
\hline Late lumen loss at follow-up & $0.049 \pm 0.17(0.08)$ & $0.163 \pm 0.17(0.17)$ & 0.018 \\
\hline Net luminal gain at follow-up & $1.96 \pm 0.51(2.0)$ & $1.79 \pm 0.62(1.67)$ & 0.063 \\
\hline \multicolumn{4}{|l|}{ OCT - proliferation analysis } \\
\hline Analyzed stent length [\%] & $95.8 \pm 9.3(95.2)$ & $91.8 \pm 11.3(87.0)$ & 0.128 \\
\hline Relative proliferation volume $\left[\mathrm{mm}^{3} / \mathrm{cm}\right.$ stent] & $2.2 \pm 8.0(2.4)$ & $7.5 \pm 6.5(8.4)$ & 0.018 \\
\hline Peak relative proliferation area [\%] & $21.6 \pm 12.2(23.1)$ & $29.9 \pm 11.5(34.0)$ & 0.028 \\
\hline Median relative proliferation area [\%] & $6.3 \pm 6.6(5.8)$ & $15.6 \pm 10.7(19.1)$ & 0.018 \\
\hline \multicolumn{4}{|l|}{ OCT — ISA analysis } \\
\hline Positive remodeling volume $\left[\mathrm{mm}^{3}\right]$ & $6.84 \pm 7.6(5.85)$ & $2.98 \pm 3.6(1.0)$ & 0.046 \\
\hline Positive remodeling volume $\left[\mathrm{mm}^{3} / \mathrm{cm}\right.$ stent] & $0.35 \pm 0.45$ & $0.16 \pm 0.18$ & 0.116 \\
\hline Number of ISA regions & $2.86 \pm 2.3(2.0)$ & $0.71 \pm 1.0(0)$ & 0.026 \\
\hline Maximal ISA depth $[\mu \mathrm{m}]$ & $452 \pm 104(49)$ & $28 \pm 40(0)$ & 0.028 \\
\hline Maximal ISA volume $\left[\mathrm{mm}^{3}\right]$ & $4.68 \pm 10.1(0.38)$ & $1.39 \pm 2.9(0)$ & 0.128 \\
\hline Total ISA volume $\left[\mathrm{mm}^{3}\right]$ & $8.37 \pm 18.3(0.38)$ & $1.54 \pm 3.2(0)$ & 0.128 \\
\hline Total ISA surface $\left[\mathrm{mm}^{2}\right]$ & $5.46 \pm 5.8(1.64)$ & $4.52 \pm 7.6(0)$ & 0.237 \\
\hline Relative ISA surface [\%] & $5.2 \pm 11.7(1.17)$ & $2.75 \pm 5.0(0)$ & 0.128 \\
\hline Struts with ISA [\%] & $16.9 \pm 13.7(16.1)$ & $5.7 \pm 7.8(0.6)$ & 0.018 \\
\hline Uncovered struts [\%] & $21.4 \pm 17.9(20.4)$ & $6.4 \pm 8.8(1.1)$ & 0.018 \\
\hline
\end{tabular}

ISA — incomplete stent apposition; MLD — minimal lumen diameter; OCT — optical coherence tomography; QCA — quantitative coronary angiography; RLD — reference lumen diameter 


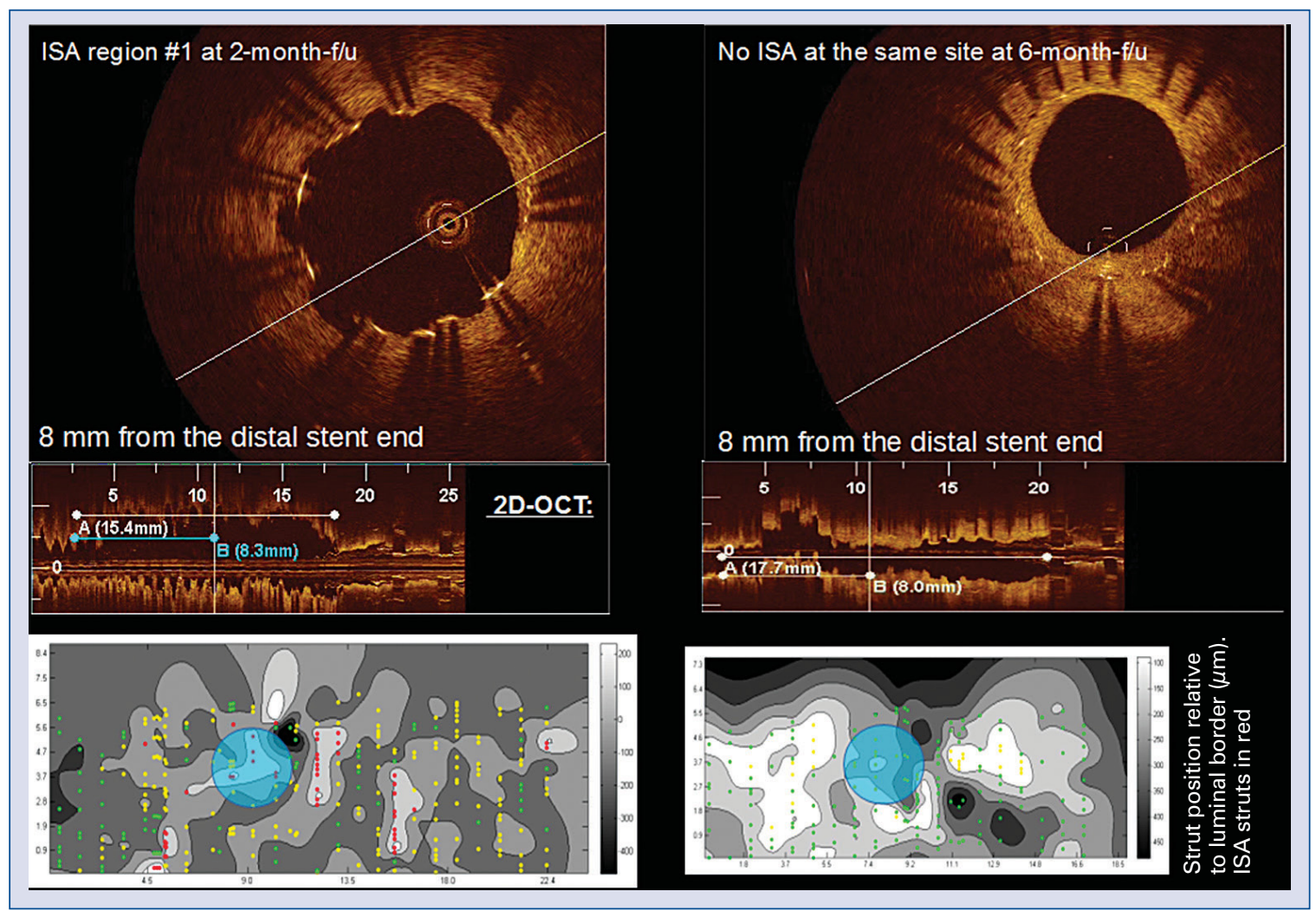

Figure 3. Serial optical coherence tomography (OCT) assessment of stent strut incorporation and neointimal growth showing resolution of an incomplete stent apposition area (ISA) between the 2-month (left panels) and 6-month results (right panels). Top: Cross-sectional two-dimensional (2D)-OCT images; Middle: longitudinal 2D-OCT views; Bottom: 3D-OCT spread-outs ("carpet-views") of the stent segment, showing the position and coverage thickness of the struts, uncovered struts in red, apposed and covered struts in yellow, embedded struts in green. X-axis - stent circumference; Y-axis - analyzed stent length. Grey scale: $(-)$ values - neointimal thickness, $(+)$ values - mal-apposition distance from luminal border. Displayed cross-section at 2-and 6-month follow-up is indicated as blue circle.

\section{Strut coverage and neointimal proliferation}

We found a high percentage of uncovered struts $(14.5 \pm 14.8 \%) 2$ months after a combination therapy of BMS + PCB. Histological studies showed an increased risk of stent thrombosis if $\geq 30 \%$ of struts are uncovered [14]. With respect to the standard deviation of our results, duration of dual antiplatelet therapy below 6 should be avoided. Stent coverage after a BMS + PCB approach is similar to those of paclitaxel- and sirolimus-eluting stents after 6 months $(\sim 5-8 \%$ uncovered struts) $[6,9,15,16]$. However, newer generation everolimus- and zotarolimus-eluting stents seem to have a better $(0.1 \pm 0.4 \%$ after 6 months) and faster stent endothelialization (4.7 $\pm 5.7-6.2 \pm 6.9 \%$ after 3 months) $[15,17]$.

\section{Incomplete stent apposition}

\section{and positive vessel remodeling}

At early 2-month follow-up we found severe ISA, which we ascribe to significant vessel wall expansion. Since we did not perform OCT at baseline, positive vessel remodeling cannot be completely proven. However, chosen stent diameters were appropriate according to RVDs and stents were well expanded. There was no clustering of areas with ISA, neither at the stent edges nor elsewhere. ISA were distributed over the entire stent length involving only small sectors and not more than a quadrant per cross-section.

Histological studies showed that paclitaxel leads to vessel wall dilation due to a decrease in media wall thickness, focal wall hemorrhage and cell necrosis $[18,19]$. Vascular enlargement after a "paclitaxel-coated balloon only" approach for $d e$ novo coronary stenosis has been demonstrated $[20,21]$. Thus, our results give the pathophysiological clue (focal positive vessel remodeling) for the increased stent thrombosis rates after BMS/PCB as previously published [13]. Furthermore, the reversibility of the observed positive remodeling phenomenon is underlined by the finding that stent thrombosis occurs early, within the first 30 days after a BMS/PCB procedure. It has been shown that 


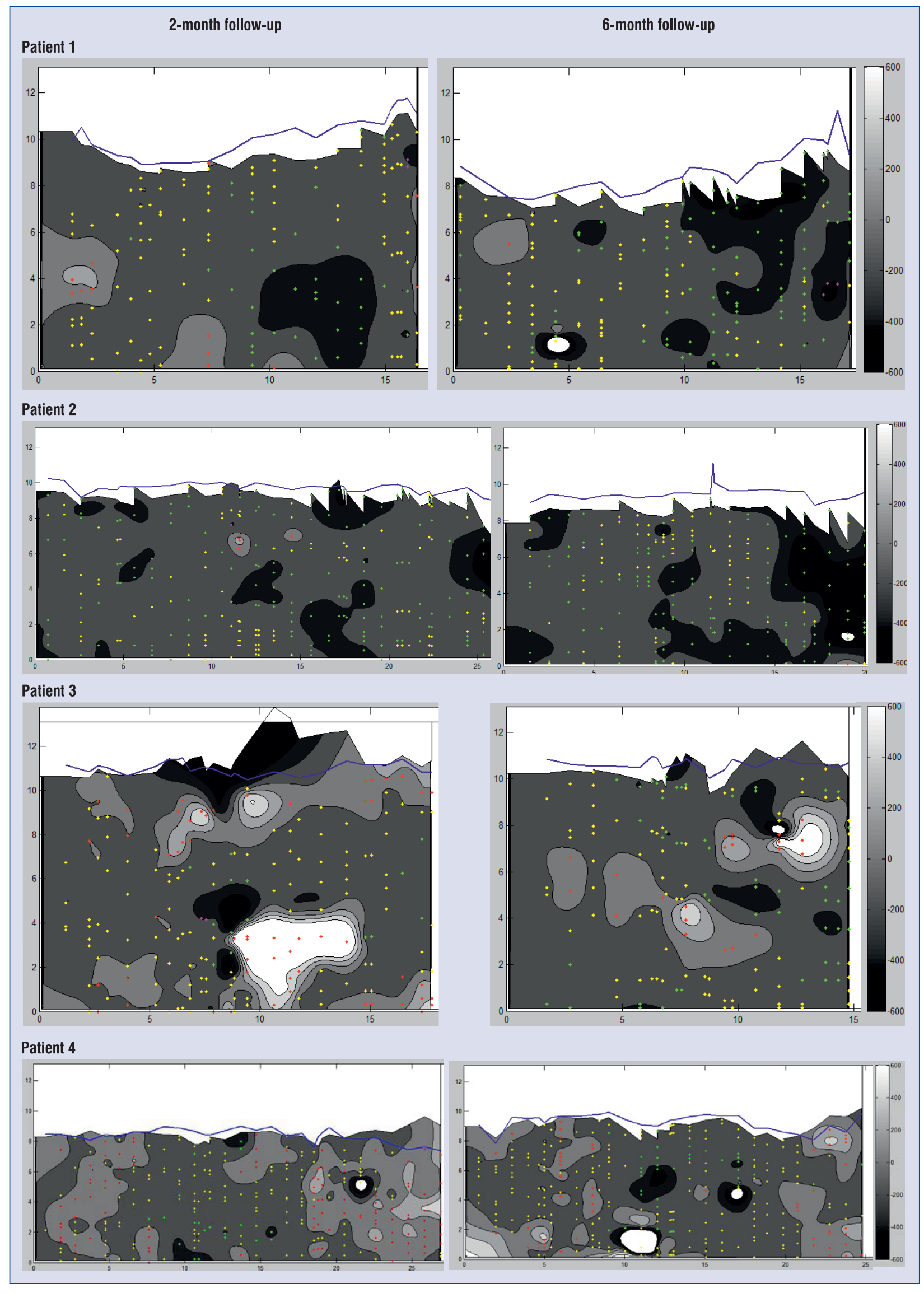




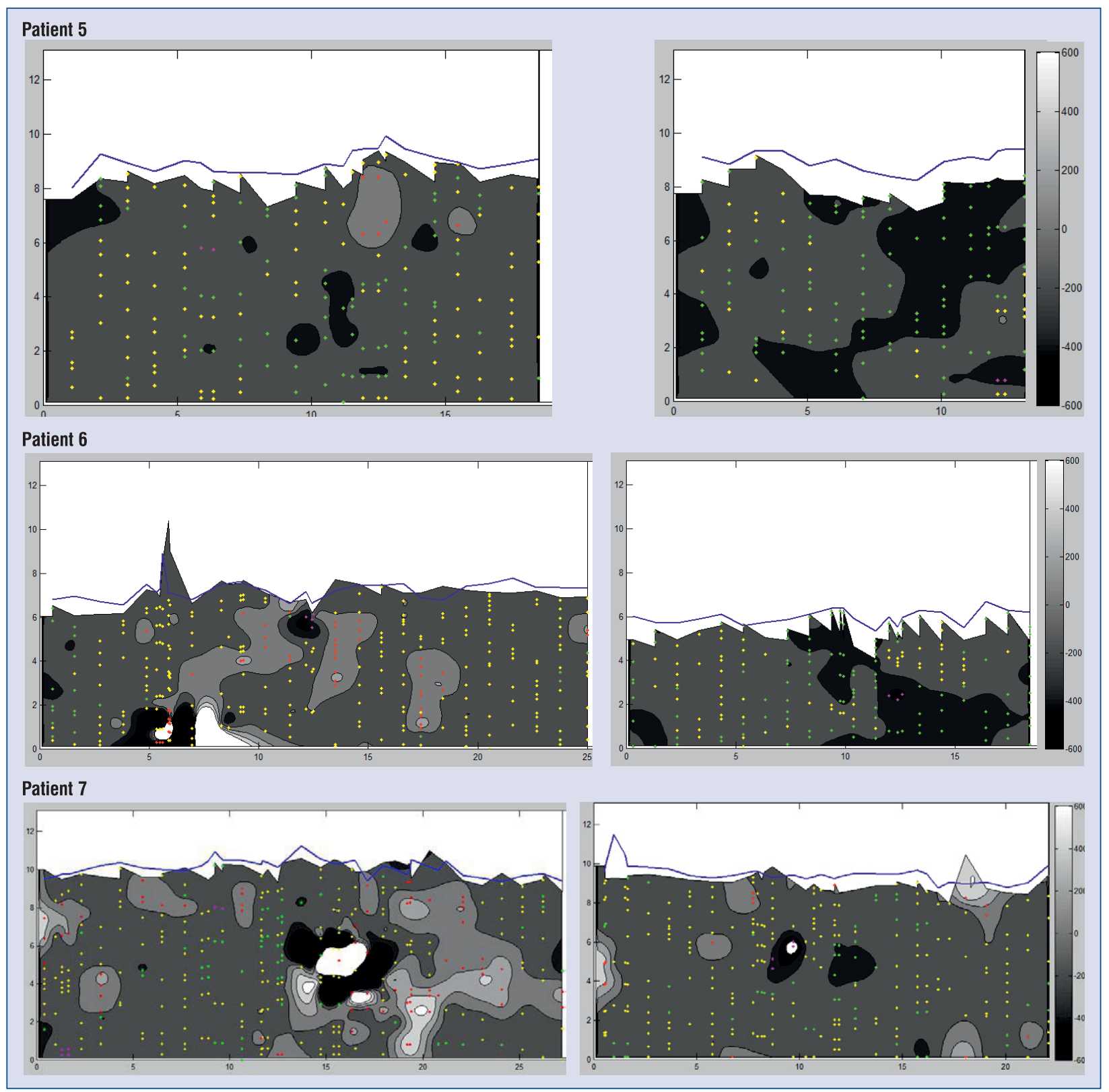

Figure 4. Three-dimensional "carpet views" — patients comparing 2-month (left column) vs. 6-month (right column) follow-up. Blue line indicates length of the circumference (perimeter) of the stent. Uncovered struts are displayed in red, apposed and covered struts in yellow, embedded struts in green. X-axis - stent circumference; Y-axis - analyzed stent length. Grey scale: (-) values - neointimal thickness, (+) values - mal-apposition distance from luminal border.

there is a delayed arterial healing for ISA depths $\geq 270 \mu \mathrm{m}$ (ISA depth at 2-month follow-up in our study: $452 \pm 104 \mu \mathrm{m}$ ) [22]. Interestingly, delivery of paclitaxel via a polymer-stent-matrix seems to induce different or rather alleviated focal vessel effects [10]. PCB induce a much higher paclitaxel tissue concentration $(\sim 300 \mu \mathrm{g} / \mathrm{g}$ tissue $)$ compared to paclitaxel-eluting stents $(\sim 3 \mu \mathrm{g} / \mathrm{g}$ tissue) [23,
24], and dose-dependent positive vessel remodeling with reversible effects at long-term follow-up have been observed [25-28]. Paclitaxel induces a higher acute inflammatory vessel reaction compared to mTOR inhibitors. Histological analysis of a BMS + PCB combination in a swine model also revealed delayed stent endothelialization and increased fibrin deposition [29, 30]. 


\section{OCT “carpet view”}

For the first time a complex algorithm based on manual input of stent struts and vessel dimensions which enables a real 3D picture of stented vessel segments as spread out was implemented ("carpet view", Figs. 3, 4). This novel comprehensive illustration of OCT-derived parameters enables recognition of strut coverage including neointimal thickness, distribution of ISA clusters and assessment of lumen and stent perimeters at a glance.

\section{Clinical implications}

We see no added clinical value for a primary strategy using BMS + PCB compared to modern DES given the large amounts of ISA after 2 months, lack of better stent coverage and the lower anti-proliferative effects [7-9, 31]. In case of bailout situations during a planned "PCB only" intervention with the need for subsequent stent implantation, short duration of dual antiplatelet therapy might be harmful.

\section{Limitations of the study}

Our patient cohort is relatively small and the study was not aligned for clinical endpoints. Calculated remodeling volumes are only surrogate parameters (better definition: vessel volume follow-up - vessel volume post-PCI) since OCT was not performed at baseline. Due to clustered data, the statistical analysis should be considered an approximation. We decided to simplify the analysis and its methodological description, since only secondary endpoints of the study were affected by this potential limitation. A true serial study was only performed in 7 patients, which is methodologically an insolvable problem, because the 2 -month/6-month groups can be statistically analyzed neither as independent nor as paired samples.

\section{Conclusions}

Bare metal stenting in combination with simultaneous application of paclitaxel by a balloon shows transient severe ISA, most likely due to focal positive vessel remodeling. Our findings underline the specific vessel effects of paclitaxel which seem to be, at least temporarily, unfavorable in combination with a stent cage. The novel 3D "carpet-view" enables for the first time the recognition of strut apposition and coverage, neointima proliferation, distribution of clusters and assessment of lumen and stent perimeters at a glance.
Conflict of interest: Sylvia Otto — Daiichi Sankyo Europe GmbH; MSD Sharp \& Dohme GmbH, Bayer Vital GmbH, Boston Scientific and BBraun: speakers bureau, travel expenses; Berlin Chemie: Advisory Board; Johannes Gassdorf - None declared; Kristina Nitsche - Travel stipend from the German Cardiac Society to attend the annual conference; Juan Luis Gutiérrez-Chico - None declared; Aleh Kryvanos - None declared; Björn Goebel - Actelion: speakers bureau, travel grants; Hans R. Figulla - Member of the European Advisory Board from Boston Scientific; Tudor C. Poerner - research grants from Abbott Vascular, BBraun and Boston Scientific, to local institutional funding, Daiichi Sankyo Europe GmbH: speakers bureau, travel grants, MSD Sharp \& Dohme GmbH: speakers bureau, Bayer Vital GmbH: speakers bureau, travel expenses, Boehringer Ingelheim $\mathrm{GmbH} \&$ Pfizer GmbH \& Nicolai Medizintechnik GmbH \& Boston Scientific \& Biotronik GmbH: speakers bureau, travel expenses.

\section{References}

1. Unverdorben M, Kleber FX, Heuer H et al. Treatment of small coronary arteries with a paclitaxel-coated balloon catheter. Clin Res Cardiol, 2010; 99: 165-174.doi: 10.1007/s00392-009-0101-6.

2. Unverdorben M, Vallbracht C, Cremers B et al. Paclitaxel-coated balloon catheter versus paclitaxel-coated stent for the treatment of coronary in-stent restenosis. Circulation, 2009; 119: 2986-2994. doi: 10.1161/CIRCULATIONAHA.108.839282.

3. Scheller B, Hehrlein C, Bocksch W et al. Treatment of coronary in-stent restenosis with a paclitaxel-coated balloon catheter. N Engl J Med, 2006; 355: 2113-2124. doi: 10.1056/NEJMoa061254.

4. Speck U, Scheller B, Rutsch W, Laule M, Stangl V. Local drug delivery: The early Berlin experience: single drug administration versus sustained release. EuroIntervention, 2011;7 (suppl. K): K17-K22. doi: 10.4244/EIJV7SKA4.

5. Ali RM, Degenhardt R, Zambahari R et al. Paclitaxel-eluting balloon angioplasty and cobalt-chromium stent versus conventional angioplasty and paclitaxel eluting stents in the treatment of native coronary artery stenosis in patients with diabetes mellitus. EuroIntervention, 2011; 7 (suppl. K): K83-K92. doi: 10.4244/ /EIJV7SKA.15.

6. Gutierrez-Chico JL, van Geuns RJ, Koch KT et al. Paclitaxelcoated balloon in combination with bare metal stent for treatment of de novo coronary lesions: an optical coherence tomography first-in-human randomised trial, balloon first vs. stent first. EuroIntervention, 2011; 7: 711-722.doi: 10.4244/EIJV7I6A114.

7. Fischer D, Scheller B, Schafer A et al. Paclitaxcel-coated balloon plus bare metal stent vs. sirolimus-eluting stent in de novo lesions: an IVUS study. EuroIntervention, 2012; 8: 450-455. doi: 10.4244/EIJV8I4A71.

8. Poss J, Jacobshagen C, Ukena C, Bohm M. Hotlines and clinical trial updates presented at the German Cardiac Society Meeting 2010: FAIR-HF, CIPAMI, LIPSIA-NSTEMI, HandheldBNP, PEPCAD III, remote ischaemic conditioning, CERTIFY, 
PreSCD-II, German Myocardial Infarction Registry, DiaRegis. Clin Res Cardiol, 2010; 99: 411-417. doi: 10.1007/s00392-010-0176-0.

9. Poerner TC, Otto S, Gassdorf J et al. Stent coverage and neointimal proliferation in bare metal stents postdilated with a paclitaxel-eluting balloon versus everolimus-eluting stents: prospective randomized study using optical coherence tomography at 6-month follow-up. Circ Cardiovasc Interv, 2014; 7: 760-767. doi: 10.1161/CIRCINTERVENTIONS.113.001146.

10. Seeger J, Markovic S, Birkemeyer R et al. Paclitaxel-coated balloon plus bare-metal stent for de-novo coronary artery disease: final 5-year results of a randomized prospective multicenter trial. Coron Artery Dis, 2015; doi: 10.1097/MCA.0000000000000314.

11. Poerner TC, Otto S, Gassdorf J et al. A prospective randomised study using optical coherence tomography to assess endothelial coverage and neointimal proliferation at 6 -months after implantation of a coronary everolimus-eluting stent compared with a bare metal stent postdilated with a paclitaxel-eluting balloon (OCTOPUS Trial): Rationale, design and methods. EuroIntervention, 2011; 7 (suppl. K): K93-K99. doi: 10.4244/EIJV7SKA16.

12. Cavallini $\mathrm{C}$, Savonitto $\mathrm{S}$, Violini $\mathrm{R}$ et al. Impact of the elevation of biochemical markers of myocardial damage on long-term mortality after percutaneous coronary intervention: results of the CK-MB and PCI study. Eur Heart J, 2005; 26: 1494-1498. doi: 10.1093/eurheartj/ehi173.

13. Zurakowski A, Buszman PP, Milewski KP et al. Stenting and adjunctive delivery of paclitaxel via balloon coating versus durable polymeric matrix for de novo coronary lesions: clinical and angiographic results from the prospective randomized trial. J Interv Cardiol, 2015; 28: 348-357. doi: 10.1111/joic.12210.

14. Finn AV, Joner M, Nakazawa G et al. Pathological correlates of late drug-eluting stent thrombosis: strut coverage as a marker of endothelialization. Circulation, 2007; 115: 2435-2441. doi: 10.1161/CIRCULATIONAHA.107.693739.

15. Guagliumi G, Musumeci G, Sirbu V et al. Optical coherence tomography assessment of in vivo vascular response after implantation of overlapping bare-metal and drug-eluting stents. J Am Coll Cardiol Cardiovasc Interv, 2010; 3: 531-539. doi: 10.1016/j. jcin.2010.02.008.

16. Guagliumi G, Sirbu V, Musumeci G et al. Strut coverage and vessel wall response to a new-generation paclitaxel-eluting stent with an ultrathin biodegradable abluminal polymer: Optical Coherence Tomography Drug-Eluting Stent Investigation (OCTDESI). Circ Cardiovasc Interv, 2010; 3: 367-375. doi: 10.1161/ /CIRCINTERVENTIONS.110.950154.

17. Kim S, Kim JS, Shin DH et al. Comparison of early strut coverage between zotarolimus- and everolimus-eluting stents using optical coherence tomography. Am J Cardiol, 2013; 111: 1-5.doi: 10.1016/j.amjcard.2012.08.037.

18. Heldman AW, Cheng L, Jenkins GM et al. Paclitaxel stent coating inhibits neointimal hyperplasia at 4 weeks in a porcine model of coronary restenosis. Circulation, 2001;103: 2289-2295.

19. Hou D, Rogers PI, Toleikis PM, Hunter W, March KL. Intrapericardial paclitaxel delivery inhibits neointimal proliferation and promotes arterial enlargement after porcine coronary overstretch. Circulation, 2000; 102: 1575-1581.
20. Poerner TC, Otto S, Duderstadt C, Figulla HR. Feasibility and angiographic 6-month follow-up of FFR-guided DEB-only elective coronary angioplasty (OCTOPUS II Study). Clin Res Cardiol, 2014; 103: V133.

21. Kleber FX, Schulz A, Waliszewski M et al. Local paclitaxel induces late lumen enlargement in coronary arteries after balloon angioplasty. Clin Res Cardiol, 2015; 104: 217-225. doi: 10.1007/ /s00392-014-0775-2.

22. Gutierrez-Chico JL, Wykrzykowska J, Nuesch E et al. Vascular tissue reaction to acute malapposition in human coronary arteries: Sequential assessment with optical coherence tomography. Circ Cardiovasc Interv, 2012; 5: 20-29, S21-S28. doi: 10.1161/ /CIRCINTERVENTIONS.111.965301.

23. Vogt F, Stein A, Rettemeier G et al. Long-term assessment of a novel biodegradable paclitaxel-eluting coronary polylactide stent. Eur Heart J, 2004; 25: 1330-1340. doi: 10.1016/j. ehj.2004.06.010.

24. Thim T, Milewski K, Tellez A et al. Biological effect on coronary restenosis of bare metal stents crimped on paclitaxel coated balloons: preliminary animal data in the porcine overstretch model. Am J Cardiol, 2009; 104: 177D.

25. Aoki J, Colombo A, Dudek D et al. Peristent remodeling and neointimal suppression 2 years after polymer-based, paclitaxeleluting stent implantation: Insights from serial intravascular ultrasound analysis in the TAXUS II study. Circulation, 2005; 112: 3876-3883. doi: 10.1161/CIRCULATIONAHA.105.558601.

26. Weissman NJ, Ellis SG, Grube E et al. Effect of the polymerbased, paclitaxel-eluting TAXUS Express stent on vascular tissue responses: A volumetric intravascular ultrasound integrated analysis from the TAXUS IV, V, and VI trials. Eur Heart J, 2007; 28: 1574-1582. doi: 10.1093/eurhearti/ehm174.

27. Weissman NJ, Koglin J, Cox DA et al. Polymer-based paclitaxeleluting stents reduce in-stent neointimal tissue proliferation: A serial volumetric intravascular ultrasound analysis from the TAXUS-IV trial. J Am Coll Cardiol, 2005; 45: 1201-1205. doi: 10.1016/j.jacc.2004.10.078.

28. Serruys PW, Degertekin M, Tanabe K et al. Vascular responses at proximal and distal edges of paclitaxel-eluting stents: serial intravascular ultrasound analysis from the TAXUS II trial. Circulation, 2004;1 09: 627-633. doi: 10.1161/01. CIR.0000112566.87022.32.

29. Buszman PP, Milewski K, Pajak J et al. Differences in vessel healing following delivery of everolimus or paclitaxel: A comparative experimental study using identical stent and biodegradable polymer platforms. EuroIntervention, 2014; 10: 724-731. doi: 10.4244/EIJV10I6A125.

30. Buszman PP, Tellez A, Afari M et al. Stent healing response following delivery of paclitaxel via durable polymeric matrix versus iopromide-based balloon coating in the familial hypercholesterolaemic swine model of coronary injury. EuroIntervention, 2013; 9: 510-516. doi: 10.4244/EIJV9I4A82.

31. Liistro F, Porto I, Angioli P et al. Elutax paclitaxel-eluting balloon followed by bare-metal stent compared with Xience V drugeluting stent in the treatment of de novo coronary stenosis: a randomized trial. Am Heart J, 2013; 166: 920-926. doi: 10.1016/j.ahj.2013.08.023. 